befindlichen Gefäßen entnommen, um $180^{\circ}$ rotiert und in den Mastektomiedefekt eingesetzt. Die dabei im Überschuß entstandene Haut-Fettgewebsschicht auf der ipsilateralen Seite wird nach Deepithelialisierung wie bei der abdominellen Verschiebeplastik für die Konturwiederherstellung verwendet. Der Film zeigt das Vorgehen im Trick und Direktaufnahme.

Schlïsselwörter: Brustrekonstruktion - Hautmuskellappen.

\title{
337. Totale Thyreoidektomie mit intraoperativer Radio-Lokalisationsmessung beim differenzierten Schilddrïsencarcinom
}

\author{
K. Littmann ${ }^{1}$, H. Fasshauer ${ }^{2}$, M. W. Strötges ${ }^{2}$, und F. W. Eigler ${ }^{1}$ \\ ${ }^{1}$ Abteilung für Allgemeine Chirurgie (Dir.: Prof. Dr. F. W. Eigler) \\ ${ }^{2}$ Strahlenklinik, Radiologisches Zentrum (Dir.: Prof. Dr. E. Scherer) des Universitätsklinikum Essen, \\ Hufelandstraße 55, D-4300 Essen 1
}

\section{Total Thyroidectomy and Intraoperative Radio-Iodine Localisation Measurement in Patients with Differentiated Thyroid Carcinoma}

Summary. This film shows a special operating procedure for thyroidectomy in patients $(n=62)$ with differential thyroid carcinoma. The recurrent nerve and the superior parathyroid gland were exposed using lateral approach. Only one patient $(2 \%)$ definitely had recurrent paresis. Using an intraoperative control method (scintillation counter, after preoperative loading of the thyroid tissue with radio-iodine) the postoperative scan was reduced significantly.

Key words: Differential thyroid carcinoma - Recurrent paresis - Intraoperative control - Scintillation counter.

Zusammenfassung. Der Film zeigt ein spezielles Vorgehen bei der Thyreoidektomie wegen differenziertem Schilddrüsencarcinom (62 Patienten). Der Nervus recurrens und das obere Epithelkörperchen werden von lateral dargestellt. Nur bei einem Patienten trat eine definitive Recurrensparese auf $(2 \%)$. Als intraoperative Kontrollmethode wird nach präoperativer Radiojodmarkierung ein Szintillationszähler eingesetzt, der es gestattet, die Restflächen, insbesondere bei voroperierten Patienten, signifikant zu senken.

Schliisselwörter: Differenziertes Schilddrüsencarcinom - Recurrensparese - Intraoperatives Kontrollverfahren mittels Szintillationszähler. 